\title{
Gnoomid, kooboldid ja goblinid. \\ Uskumusolendite nimetuste tõlkimise spetsiifikast
}

Reet Hiiemäe

doi:10.7592/PS/28-2hiiemae

Teesid: Artikkel annab ülevaate uskumusolendite nimetuste tõlkimisel ilmnevatest probleemidest, näiteks kuidas toimida siis, kui sõna keeleline või usundiline vaste sihtkultuuris puudub või kui sellel on sihtkeeles lähtekeelega sarnane kirjapilt, kuid erinev sisu. Peamurdmist valmistavad olukorrad, kui ühes keeles on teatud olendite jaoks detailsem klassifikatsioon kui teises, samuti juhtumid, kui osa olendinimetusest on tõlgitav, kuid osa mitte, või kui mingi termin on lähtekeeles paralleelselt kasutusel nii üldnimetuse kui originaalnimena. Tõlkeraskusi esineb polüteistliku ja monoteistliku usundi maailmapildi erinevuste pinnal, samuti soolisuse edasiandmisel. Eksimuste vältimiseks on vajalik tunda nii vastava sõna päritolukultuuri kui seoseid sihtkultuuriga, samuti olla teadlik kasutuskontekstist. Lisaks on huvipakkuv olendinimetuste tõlgete roll inimeste empiiriliste kogemuste ja nende kirjelduste vormimisel.

Märksõnad: tõlkimine, usund, üleloomulikud olendid, empiiriline kogemus, kultuuriline kontekst

\section{Sissejuhatus}

Olulisi tõukejõude uskumusolenditega seotud terminoloogia üle järelemõtlemisel oli mulle Austria professori Leander Petzoldti raamatu "Väike deemonite ja vaimolendite leksikon" tõlkimine eesti keelde ja kommentaaridega varustamine. Selle ja teiste usun- 
dialaste tõlgetega seoses sai üha selgemaks, et kultuurilise tausta tundmine pole oluline mitte ainult teiste kultuuride oluliste ilukirjandus- ja pärimustekstide (nt eeposte) tõlkimisel, vaid isegi ainult ühe sõna (nt mütoloogilise olendi või kultuseseme nimetuse) tõlkimisel võib osutuda vajalikuks tunda nii selle päritolukultuuri kui seoseid sihtkultuuriga ehk vastavat tähendusvälja laiemalt, olgugi et ka sihtkeele vaste koosneb sageli sisuliselt ainult ühest sõnast. Artikkel annab ülevaate mitmetest uskumusolendite nimetuste tõlkimisel esilekerkivatest probleemkohtadest, kusjuures selgub, et dilemmasid esineb nii laialt tuntud olendinimetuste, nagu nõid, päkapikk, majavaim, kui ka spetsiifilisemate ja lokaalsemalt tuntud usundiliste terminite, nagu $d r u d$, goblin, tõlkimisel. Nii mõnedki tõlkenäited on toodud ülalmainitud vaimolendite leksikonist, kuid puudutatakse ka teisi keele- ja kultuuripaare. Kuid artikkel ei püüa pakkuda universaalseid valmislahendusi, vaid eelkõige juhtida tähelepanu erinevatele võimalustele komistuskivide ületamisel.

\section{Uskumusolendeid puudutava (tõlke)sõnavara aktuaalsus ja mõju maailmakirjeldamise viisidele}

Kanooniliste religioonide tähtsuse taandudes ja seoses ebakindlustundega tuleviku suhtes on nii Eestis kui üldse Euroopas ja mujal arenenud riikides inimeste huvi usundite ja usundiderivaatide vastu viimastel kümnenditel jätkuvalt suurenenud. Märkimisväärne on nende inimeste hulk, kes tunnevad end isiklikult kogevat kontakte vaimumaailmaga, nagu poltergeistide, luupainajate, kummituste, kaitseinglite või kuradiga, kusjuures kohatavate olendite spekter on kultuurilise globaliseerumise käigus muutunud järjest mitmekesisemaks. Näiteks on suuresti just viimaste aastakümnete vastavasisuliste tõlgete teene see, et inimesed on hakanud tõlgendama energianappust energiavampiiride kätetööna või kirjeldama oma meditatsioonikogemust kui kohtumist mõne daakini või šaktiga. 2011. aasta detsembris kutsuti muuhulgas soovijaid jõulumeditatsioonile ükssarvikutega. 
Samuti on tõlgete mõjul muutunud vaimolendite poole pöördumise laad: kui traditsiooniliselt suheldi nendega pigem palve või loitsu teel, siis mitmed viimaste aastate tõlkeraamatud ja nende mõjul ka esoteerilised õpetajad soovitavad esitada kas universumile või vastavale olendile taotlusi (nt Krayoni raamatud ${ }^{4}$ ). Niisiis võib öelda, et lisaks sellele, et tõlkimine mõjustab keelt ja kultuuri - mida on sedastanud paljud tõlketeoreetikud -, mõjustab see ka üksikisiku empiirilist kogemust.

Tõlked ja eestindused katsetavad kultuuri assimileerimis- ja omaksvõtmisvõimet ja selle piire, näiteks on üldkasutatavaks saanud neologismid jeti ja voodoo, zombi ja humanoid, kuigi otsest Eesti kultuuri analoogi, millele tugineda, neil pole. Mõne mõiste omaksvõtuks võib kuluda aastaid, mõni jääbki eksisteerima paralleelselt sihtkultuuri vanemas kihistuses tuntud kujutelmadega (nt Eesti vana veevaimukujutelm versus laenuline Melusine), kuid on ka selliseid, mis ei saavuta haakumist sihtkultuuri mentaalse maailmaga ja jäetakse kõrvale.

Info- ja kultuurivahetus toimub mõlemasuunaliselt: järjest suureneb eesti unikaalse rahvapärimuse tutvustamine väljaspool eesti keeleruumi, samas tõlgitakse eesti keelde arvukalt mütoloogia ja pseudomütoloogia alaseid väljaandeid teistest keeltest. Populaarsete fantastika valdkonda kuuluvate teoste (eesotsas "Harry Potteri", "Kääbiku” ja "Sõrmuste isandaga") juured on rahvapärimuses ning paljude olendite prototüübid ja maagiavõtted vanemast usundist laenatud ja adapteeritud. Populaarne on valdkonna mänguline kasutus, juba aastaid tegutsevad uskumus- ja fantaasiaolenditel põhinevate rollimängudega tegelevad kildkonnad(nt fantastikahuviliste portaal http://www.dragon.ee, Tolkieni-huviliste veebileht http://www.keskmaa.ee). Samuti leidub olendeid puudutavaid rubriike ulmelistides, -blogides, -foorumites (nt ulmehuviliste meililistis sf2001; viimasel ajal www.ulme.ee) ja esoteerikafoorumites, kus võib muuhulgas kohata tuliseid terminoloogilisi, tõlke- ja tõlgendamisteemalisi vaidlusi (nt kas olend, kellega inimene kohtus,

4 Vt http://www.hot.ee/emfestonia/Kontakt_1.6.html (vaadatud 12.09.12) 
oli painaja, inimese enda vaimuteisik, pahatahtlik tulnukas või energiavampiir).

Ka tänapäeva filmikunst otsib sageli inspiratsiooni mütoloogilisest maailmast, õudusfilmides kohtame moderniseeritud, kuid äratuntavalt traditsiooniliste sugemetega monstrumeid, kummitusolendeid, koletisi, deemonlikke alter egosid jms. Fantaasiafilmide ja -kirjanduse puhul kasutatakse fantaasiaolendite loomisel pärimusolendeid teadlikult enamasti ainult algmaterjalina. Samuti ei taotleta tingimata terminoloogilist korrektsust. Ometi kerkivad materjali teistesse keeltesse tõlkimisel siingi üles samad küsimused nagu traditsiooniliste olendinimetuste puhul, mistõttu oleks sellegi valdkonna puhul orienteerumine traditsioonilises usunditerminoloogias teretulnud.

Oma roll on mütoloogilistel olenditel ja nende nimetustel turismitööstuses, kuna turistide jaoks kujundatakse sageli mõnest atraktiivsest usundilisest figuurist rahva või maa visiitkaart. Nii esitlevad meile reisikorraldajate reklaamiprospektid Norrat kui trollide maad, Kreekat seostatakse antiikjumalatega, Paani ja nümfidega, keltide kultuuriloost rääkides meenub kuningas Artur (Artus) ja tema õukond, aga ka lohed ja jumalused jne. Piirkondade turismibuklettides mainitakse majades ja lossides ringi käivaid kummitusi (nt Haapsalu lossi Valge Daam, Tallinna Harju värava kummitus, Tartu kirjandusmuuseumi Lilla Daam jne).

Samal ajal on Eestis otseselt usundi- ja mütoloogiaolenditega seonduvat terminoloogiat käsitlevaid sõnastikke ja leksikone võrdlemisi napilt. Vajadus saada ühtsem pilt nende tihti juba olemuselt ambivalentsete ja keeruka päritolu- ja levikulooga uskumusolendite paljususes on aga olemas. Selles osas pakkusid võrdlusena positiivse üllatuse mõningate Euroopa maade usundihuviliste ringkondade algatused - olendidefinitsioone otsides leidsin juba mõned aastad tagasi rea temaatilisi, sageli muljetavaldava kujundusega, kuid sisult asjatundlikke veebilehti (nt saksa keeles http:// www.daemonen.de; http://www.geisterarchiv.de; http://www. enctype.de/Daemonen/frame.htm; inglise keeles http://www.eaudrey.com/myth), mis annavad vastava olendi definitsiooni või kirjel- 
duse, selgitavad nimetuse päritolu ja heal juhul pakuvad ka vasteid teistes keeltes.

\section{Uskumusolenditega seotud terminoloogia tõlkespetsiifikast}

Peeter Toropi sedastus, mille kohaselt tõlkija ei pea olema mitte niivõrd lingvist kui kulturoloog ning tähtsamaks kui keele tundmine võib osutuda kultuuri tundmine (Torop 2003), kehtib usundinähtuste tõlkimisel eriti, kusjuures lisaks lähte- ja sihtkeelele peab sellise materjali tõlkija tundma ka muid kommunikatiivseid komponente: vastavate kultuuride sümboleid, tabusid, koodkäitumist jms. Ühtlasi tuleb jälgida, et ühte kultuuri ei tõlgitaks teiseks kultuuriks, vaid kultuur peaks jääma ikka samaks, kuid teises keeles mõistetavaks. Siiski määravad just tõlkija rohkem või vähem teadlikud valikud selle, kas tema tõlke põhisuund on pigem võõrapärastav ehk lähtekultuuri- ja keelt rõhutav või kodustav-mugandav ehk sihtkultuurile ja -keelele keskenduv. Saksa filosoof Friedrich Schleiermacher märkis juba oma 1813. aastal ilmunud tõlkemeetodeid kirjeldavas käsitluses, et tõlkijal on piltlikult öeldes kaks valikut: kas viia lugeja originaalmaterjali juurde või originaalmaterjal lugeja juurde (Schleiermacher 1813).

Loomulikult on tõlke puhul oluline selle sihtrühm (nt täiskasvanud tavalugejad, lapsed) ja funktsioon (nt teaduslik, meelelahutuslik, õhustiku edasiandmisele suunatud). Tõlkides olendinimetusi folkloristide jaoks on vaja enamasti vähem lahtiseletamist, definitsioone ja joonealuseid märkusi kui laiemale lugejaskonnale mõeldud tekstis. Näiteks on tavalugejale mõeldud haldjaid tutvustavas raamatus pakutud ingliskeelse sõna dryad tõlkena drüaad (puunümf) (Marriott 2009). Kui tõlke adressaat oleks usundiuurija, oleks tõenäoliselt piisanud ka ainult sõnast drüaad. Seevastu lastele mõeldud tõlgetes on enam põhjendatud kodustav-adapteeriv, võimalikult eestipärasele sõnakasutusele orienteeritud tõlkemeetod. Lisaks on tõlkimise puhul oluline arvestada, kas mingi termin 
paikneb selgitavas kontekstis või moodustab pelgalt osa paarisõnalisest kõnekujundist või vahemärkusest.

Näide:

Painaja (saksa k Alb, Alp, Elphialtes). Saksakeelne painaja nimetus 'Alb, Alp' on tuletatud anglosaksi ja alamsaksa sõnast alf, elf 'haldjas', märkides algselt anglosaksi ja Vana-Skandinaavia pärimusemütoloogilisi haldjaid. Painaja nimetuse alla on rahvausundis koondunud väga erinevad kujutelmad, mis peegelduvad ka regionaalsete nimetuste paljususes. Algselt sõbralikust olendist arenes juba varakult salakaval rõhujaolend, keda piirkonniti tuntakse kõige erinevamate nimetuste all: Hessenis, Frangimaal, Tüüringis, Saksimaal 'Alb', Baieri-Austria alal Trut, ${ }^{\star}$ drud, alamsaksa keelealal ${ }^{\star}$ mahr, Svaabimaal ja Alemanni piirkonnas ${ }^{\star}$ schratt ja Ida-Friisi ja Oldenburgi kultuuriruumis Walrider... (lühendatult raamatust: Petzoldt, Hiiemäe 2010)

- dich hat der Nachtalb geritten

(Saksa rahvapärane ütlus)

- $\quad$ käib peale kui painaja; nagu luupaine käib selga

(Eesti rahvapärased ütlused)

Nagu enamiku muugi materjali tõlkimisel, tuleb ka usundiliste nähtuste puhul olla teadlik tõlkimise mitmemõõtmelisusest, mille puhul olulisemad on:

sünkroonne mõõde (tõlkimine sama piirkonna mitme kultuuri vahel või geograafiliselt eri paikades asuvate kultuuride vahel) ja diakroonne mõõde (tõlkimine varasemast ajast hilisemasse).

\section{Näide:}

$\mathrm{Mu}$ eelkooliealised lapsed leidsid vanaema juurest lambarauad ja küsisid, mis need on. Vastus ei saa piirduda ühe sõnaga, vaid peab hõlmama ülevaate vana aja rõivastumistavadest, rõivaste valmistamise viisidest, nende seostest lambapidamisega, heal juhul ka täienduse, et lambaraudadele (nagu muudelegi metallesemetele) 
omistati usundis pahatahtlike üleloomulike olendite eest kaitsvat tähendust, siit aga johtub juba vajadus täpsustada, kes olid need kurjad olendid, kuidas neid nimetati jne. Lõpuks on vajalik veel piiritlev märkus, et multifilmist nähtud rebaserauad on funktsioonilt teistsugused kui lambarauad, kuigi mõlemad sõnad kõlavad eesti keeles samamoodi.

Seega muutub eri ajastutel ka ühe keele ja kultuuri piires sama sõna tähendusspekter. Ühes ajastus aprioorsed kujundid võivad olla teises mõistetamatu eksootika ja vajada tõlkimist. Teisalt pole ka sünkroonne mõõde konstantne suurus - mõned võõra eksootilise kultuuri terminid ja terved terminikompleksid võivad ajapikku sihtkultuuris kodustuda ja igapäevaseks muutuda. Samuti nagu rahvapärimuses on ka sõnavara puhul olemas kasutamise aktiivne ja passiivne faas. Passiivses faasis võidakse veel teada, mida mingi sõna tähendab, aga seda mitte enam kasutada. Esineb olukordi, kus juba teatakse, mida mingi võõrast kultuurist laenatud termin tähendab, kuid selle sisenemine üldisesse aktiivsesse keelekasutusse võib toimuda tunduvalt hiljem.

Samasugust ühest ajastust või kultuurist teise tõlkimise funktsiooni täidavad näiteks muuseumid (muuseumitõlke kohta vt nt Sturge [2012]), kusjuures tõlge võib külastaja jaoks määrata eseme mentaalse ja vahel ka rahalise väärtuse. Näiteks ilma selgitava tekstita oleks unikaalne meteoriiditükk lihtsalt üks silmatorkamatu kivi, alles teadlikkus selle erakordsusest annab külastajale selle tähenduslikkuse tajumisel uued raamid.

Kirjeldatud näidetega seoses on asjakohane märkida tõlkeobjektide jagunemist mentaalseteks ja esemelis-kujutiselisteks. Kui lambaraudade või meteoriiditüki puhul saab tõlget toetada pildiline või esemeline kujutis, siis olendite kohta fotosid üldjuhul pole. Mõningate olendite kohta on küll olemas vastava kultuuri usunditraditsiooni mõjutustega joonistusi ja maale, kuid need on lõppkokkuvõttes siiski üksikautorite subjektiivsed tõlgendused.

Siin jõuame välja mitmete kultuuriteoreetikute seisukohani, et kogu kultuuri tuleks tegelikult mõtestada tõlkeprotsessina, näiteks lingvist ja antropoloog Michael Agar leiab, et kultuur tervikuna on juba ise konstruktsioon, tõlge allika ja tulemi vahel (Agar 2006: 
5-6). Peeter Torop (2011: 193) märgib, et tõlge ja kultuur on loomuldasa kokkukuuluv mõistepaar - tõlge on kultuuriline ja kultuur tõlkeline nähtus.

\section{Uskumusolenditega seotud terminoloogia ajaloost}

Varasematel aegadel on ilmunud Eestis vähe selliseid käsitlusi, mis kõrvutaksid usundi- ja mütoloogiaolendite erikeelseid nimetusi ja/ või definitsioone.

Uskumusolendite terminoloogia valdkonnas on üks esimesi leksikonilaadseid ülevaateid F. J. Wiedemanni (1876) "Aus dem innerem und äusseren Leben der Ehsten”, mis sisaldab üsna põhjaliku peatüki uskumusolenditest koos definitsioonide ja eesti-saksa tõlgetega. Mitmed eestikeelsed terminid on Wiedemann lahti seletanud kirjelduse kaudu, ilma vastet välja pakkumata, nagu näiteks: "Kratt (schwed. skratt), krätt, raha-rett ist ein Geist oder Kobold, welcher seinen Besitzer an Uebelthätern rächt und ihm Glück und Wohlstand bringt...” [Kratt (rootsi k skratt), krätt, raha-rett on vaim või koobold, kes enda omaniku eest pahategijale kätte maksab ning omanikule õnne ja rikkust toob] (Wiedemann 1867: 427). Wiedemannil esineb küll ka mõningaid põhimõttelisi vigu, näiteks väidab ta, et: "Lendva (der Fliegende, Drache) oder vedaja (der Schlepper) mögen vielleicht nur andere Namen für den kratt sein" [Lendva või vedaja on ehk lihtsalt teised nimetused krati kohta] (Wiedemann 1867: 428). Tegelikult on lendva kui projektiilhaiguse olemus varavedaja omast siiski kardinaalselt erinev, kui välja arvata see, et mõlemad tekitavad kahju enda omaniku teenistuses ja käsul. Samuti ei tee Wiedemann vahet kirjanduslikku päritolu pseudomütoloogia ja rahvaehtsa mütoloogia olenditel.

Olulist lisainformatsiooni vanemate käibel olnud rahvapäraste usunditerminite kohta annab S. H. Vestringi väga rahvalähedane, teistest omaaegsetest tunduvalt mahukam sõnaraamat "Lexicon Esthonico Germanicum”, mille Vestring koostas 18. sajandi teisel 
ja kolmandal aastakümnel ning mis muuhulgas sisaldab ka olulisi usundilisi termineid, nt Härja Pölwe-Rahwas - Zwerge; Kol - Der Popantz, Lendwa Maddo - Der Drache, Liwa Annus - Der Tod, Näk - Ein Wasser Gespenst Sirene. Viimase vaste puhul tuleb siiski märkida, et Kreeka mütoloogiast lähtuval ja hiljem ka Euroopa romantilises kirjanduses meelsasti kasutamist leidnud terminil Sirene on eesti näkiga ainult üsna kauge analoogiaseos.

Oluline nii uskumusolendite kui nendega seostuva terminoloogia kirjeldaja ja võrdlejana oli Oskar Loorits (1900-1961), tema uurimistöö põhjalikumaid väljundeid on monumentaalne saksakeelne teos "Grundzüge des estnischen Volksglaubens" (19491957). Lisaks paljudele muudele defineerib ja võrdleb Loorits selliseid termineid, nagu näiteks Zieher ja Feuerschwanz < kratt, varavedaja; Schutzgeist < kaitsevaim; Alp < luupainaja jpt. Looritsa omapära on julgete sõnasõnaliste tõlgete tegemine, mille sisu jääb nii mõnigi kord lähtekeele lugejale segaseks, nt kadunuke < Verschwundene; tuulispask < Windkot; vanapagan < alter Heide. Märkimisväärne on Looritsa puhul sõna Dämon liigtarvitamine vastena eesti neutraalsemale terminile vaim või haldjas, samuti esineb muidu ettevaatamatuid tõlkeid, nt märgib Loorits, et ihnetest ja ülbetest inimestest saavad majakooboldid (Hauskobold), kes viskavad toidu- ja pesunõusid ümber, lõhuvad ja kolistavad (Loorits 1957: 168). Kirjelduse järgi on tegemist siiski hauast käiva kodukäijaga, mitte majas püsivalt elava majavaimuga, kelle kohta germaani kultuuriruumis kasutatakse sõna Kobold.

1925. aastal ilmunud I. Mannineni "Etnograafiline sõnastik" (Manninen 1925, uustrükid 1979 ja 1993) oli teadusmaastikul tähelepanuväärne selle poolest, et pani aluse etnograafilisele terminoloogiale Eestis. Uuemal ajal ilmunutest väärib märkimist "Eesti rahvakultuuri leksikon", mis sisaldab viiekeelset temaatilist sõnastikku (Viires 1995), kuid on samuti esmajoones pühendatud ainelise kultuurivara terminitele, puudutades põgusalt vaid mõndakümmend uskumusolendit, nagu: dummer Teufel < vanapagan; Erdgeist < maajumal; Erdmutter < murueit; Gespenst < kummitus, tont jne. Neidki olendivasteid kriitiliselt analüüsides tekib küsimus, kas murueit kui romantilise tõlkekirjanduse pitseriga sõna poleks 
parem asendada eesti usundile omasema maaemaga ja maajumal hierarhilises mõttes vähem pretensioonika sõnaga maavaim. Mõnede üksikolendeid puudutavate uurimistööde raames on vaadeldud ka käsitletava olendi nimetuse etümoloogiat ja paralleele teistes keeltes, kuid need piirduvad kitsalt käsitletavat teemat puudutava olenditerminoloogiaga (nt maa-alused - Hiiemäe, M. 2003; näkk, veevaimud - Eisen 1922).

\section{Tõlkimisel esile kerkinud probleemkohti}

\section{Tõlkepiirid}

Torop (2011: 157) märgib tõlkepiiridest rääkides, et vahet tuleb teha kahe piiri vahel: "piir tõlke ja originaali vahel ning piir tõlke ja vastuvõtva kultuuri vahel” - seega ühelt poolt, kas sõna on tõlgitav ehk kas sõna sisu edasiandev vaste on olemas, ja teisalt, kas vaste on sihtkultuuris mõistetav. Rahvausundi kontekstis ei tohi unustada, et sarnaste motiivide, tunnuste või olendihierarhiate olemasolu eri kultuuriruumides ei tähenda, et uskumuste või uskumusolenditega seotud kujutelmade vahel võiks tingimata eeldada geneetilist seost. Isegi kui selline seos on olemas, pole näiteks eesti päkapikk sama, mis on germaani Zwerg, samuti pole meie jõuluvana sama mis Santa Claus või Father Christmas. Päkapikk on Eesti kultuuriruumis uustulnukas, üle võetud kirjanduse kaudu teiste maade gnoomide ja kääbusolendite mõjul (nt juba Kreutzwaldi muinasjuttudes (esmatrükk 1866) figureerivad muude saksa kultuurist kohandatud motiivide hulgas laenuliste sugemetega härjapõlvlased). Ühe mõne aasta taguse jõuluaegse ajalehe järgi aga toovad lastele sussi sisse kingitusi nimelt "heatahtlikud gnoomid" - taas üks näide tõlkepiiridesse kergekäeliselt suhtuvast tõlketegevusest.

Leidub teisigi pealtnäha väga sarnaseid uskumusolendeid, kuid siiski ei ole näiteks Eesti näkk sama, mis Inglise veevaim. Erinevalt Eesti valdavalt magevees tegutsevast uputajaolendist ilmub Inglismaal veevaim pigem merest ja tal on esmajoones tormi eest hoiataja funktsioon, alles teisene funktsioon on olla deemonlik uputaja. Siia 
võib paralleelina tuua veel kolmanda kategooria, mis on edasiarendamist leidnud peamiselt saksa romantilises kirjanduses, nimelt ahvatlevad neidised, nagu Melusine ja Lorelei, kes meelitavad vette ja lõppkokkuvõttes samuti uputavad kergeuskliku inimese, kuid kes kindlasti pole pärisasukad eesti usundis, kuigi tõlkeraamatuna on Melusine-lugu ka Eestis ilmunud. ${ }^{5}$ Kultuuritausta arvestamata üksühene nimetuste ülekandmine oleks kas lausa eksitav või vähemalt riskantne ettevõtmine. Kuigi mitmete eesti uskumusolendite puhul võib oletada germaani mõjutusi, ei saa neid käsitleda automaatselt kui germaani laene, nagu seda usundiuurija Oskar Loorits sageli on teinud.

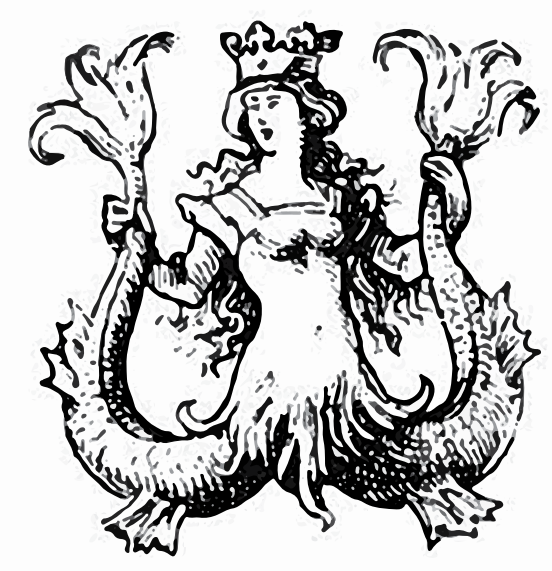

Melusine

2. Polüteistliku ja monoteistliku maailmapildi kokkupuutel tekkivad tõlkeraskused.

Eesti kaitsevaimude saksakeelse vastena on eriti vanemates tõlgetes kasutatud sõna Gott. Näiteks Wiedemann (1876) pakub välja tõlkekombinatsiooni: Kodujumal - Hausgott. Rahvakultuuri leksikon (Viires 1995) toob ära seose: Erdgeist < maajumal. Kuid eesti usundi kõrgajal polnud ainujumala idee uskumusolendite süs-

5 Hofmann, Heinrich; Osterwald, Wilhelm; Mägi, Otto. Ilus Melusine. Jurjev 1898. 
teemi kuigivõrd üle võetud ning nii ülaltoodud kodujumala kui maajumala puhul oleks tegelikult põhjust rääkida piirkondlikest kaitsevaimudest ja mõttekas hoiduda eksitavast sõnast jumal, mis germaani kultuuriruumis seostub siiski esmajoones monoteistliku taevajumala kujutelmaga. Ilmeka näite selle kohta, kuidas mingi tõlkevaste hakkab ühest teosest teise kandudes vohama ja võib luua väärpildi tegelikkusest, saab tuua omaaegsest esinduslikust monumentaalteosest "Handwörterbuch des deutschen Aberglaubens", milles tsiteeritakse ühe M. J. Eiseni töö saksakeelset tõlget ja märgitakse: "Die Esten haben Tõnn gar zum Schweinegott gemacht"6 (HDA I: 505). Tegelikkuses on jutt pühak Antoniusega seoses olevast Tõnnist, kes on eesti usundis täitnud ainujumalaga võrreldes üsna tagasihoidlikku sigade kaitsevaimu funktsiooni.

Üks olulisi erinevusi on asjaolu, et eesti usundilised olendid on üldiselt vähem demoniseerunud kui Kesk- ja Lääne-Euroopa piirkonnas (nt Saksamaa, Itaalia, Austria, ka Rootsi) esinevad. On tõsi, et ka Eestis hakkasid muidu neutraalsed või isegi heatahtlikud vaimolendid ristiusu mõju suurenedes samuti vähehaaval demoniseeruma, kuid siiski tagasihoidlikumal määral kui nimetatud piirkondades üldiselt, põhjuseks nii keelebarjäär jumalasõna levitamisel kui Eesti geograafiliselt perifeerne paiknemine, mistõttu pole duaalne jaotus eesti usundi olendkonnas üldjuhul nii kontrastne. Seega osutub siin tõlkimisel arvestamist vajavaks kultuuriliseks komponendiks psühholoogiline aspekt, nimelt hirmu faktor - ühes kultuuris seostub sama olendiga numinoosne hirm, teises mitte.

Eelnimetatud põhjustel ei ole eesti kontekstis sageli põhjendatud ka deemoni mõiste kasutamine viimase negatiivse konnotatsiooni tõttu, pigem sobib neutraalsem sõna vaimolend, vaim. Kindlasti on terminid deemon ja vaimolend osaliselt kattuvad, ehk täpsemalt vaimolendid on katusmõiste, mis hõlmab muuhulgas ka deemoneid, kuid selle alla kuuluvad laiemalt nii negatiivsed kui positiivsed, pahatahtlikud kui heatahtlikud olendid. Niisiis on põhjust olla ettevaatlik ja mitte mehhaaniliselt asendada ühe kultuuri märke

6 Eestlased on Tõnnist lausa sigadejumala teinud. 
teise omadega (vrd Torop 2003). Kui saksa usundi kontekstis on täiesti aktsepteeritav rääkida olenditest nimega Korndämonen, siis nende eesti suguvendade puhul oleks vaste viljadeemon kasutamine ebatäpne, asjakohasem oleks viljavaim või mõningatel juhtudel viljahaldjas. Samas tuleb jälgida iga konkreetset juhtu eraldi, näiteks sõna Gespenst vasteks sobib nii kummitus kui tont. Arvestades usundilist sisu on kummitus täpsem vaste. Skandinaavia laensõna tont (soome $\mathrm{k}$ tonttu, rootsi $\mathrm{k}$ tomte) on Eestis piirkondlikult tuntud ja selle taga peituv olend on olemuselt deemonlikum, sarnane-

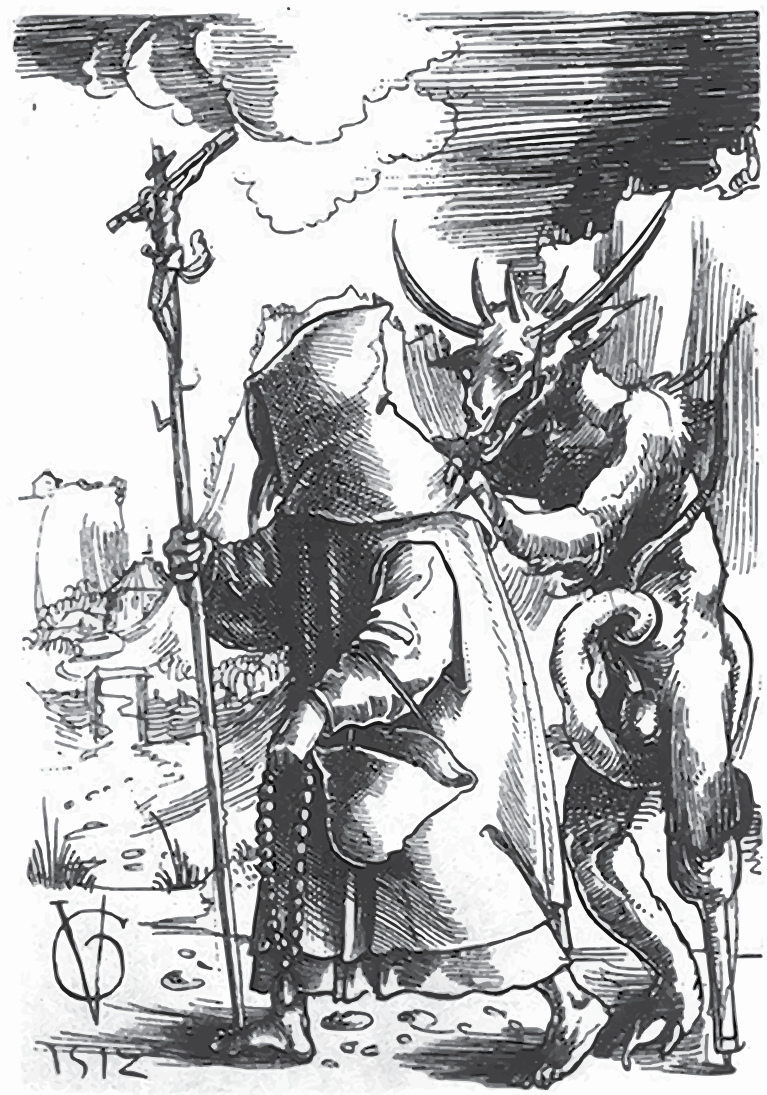

Vanemas euroopa kultuuris kujutati kuradit üldiselt hirmutava ja inimeste käitumist distsiplineerivana. Kurat kimbutab munka. Sulejoonistus. 1512. 
des enam kuradiga (tont, vanatont on ka üks kuradi eufemisme), Virumaa tekstides esineb tont lisaks veel ka varavedaja rollis. Seega võib tont sobida valitud kontekstides eriti pahatahtlikult käituva kummitusolendi tõlkevasteks. Samuti pean õigeks säilitada vene kodukäijakujutlema tutvustavas tekstis vene mõistet domovoi (vrd nt Marriott 2009: 171-172), kuna vene kodukäijal võivad esineda lokaalsed erijooned (eriti omane on deemonliku ja vägivaldse käitumise domineerimine).

\section{Puuduv vaste}

Tõlketeoreetik Sider Florin (1993: 125) väidab seoses reaalidega ehk objektide ja fenomenidega, mida sihtkultuuri lugeja ei tunne ja mille kohta sihtkeeles vastet pole, et need ongi oma olemuselt üldjuhul tõlkimatud. Juhtudel, kui mingi märksõna eestikeelne tõlkeline või usundiline vaste puudub, on tihti ainus võimalus originaaltermin enam või vähem eestipärastatud kujul alles jätta (transkribeerida). Kui neid transkribeeritud originaaltermineid tõlkes kasutada, on üldjuhul vajalik selgitav lisakommentaar (nt joonealune märkus, selgitav laiendus tekstis, sõnaseletused teksti lõpus), muidu võib termini sisu jääda lugeja jaoks varjatuks. Näiteks aitab asjassepuutuvat lähtekultuuri mittetundvat inimest lisatud ühesõnaline eesti usundiga haakuv täiendus: "koduhaldjad brownie'd" (Marriott 2009: 172) või "koduhoidjahaldjas bean tighe" (Marriott 2009: 170). Sealjuures on kogemus näidanud, et geograafiliselt, keeleliselt ja kultuuriliselt kaugete ning seega eesti usundiga vähehaakuvate olendite nimetustega on lihtsam kui lähedasematesse kultuuridesse kuuluvatega, kuna kaugete kultuuride puhul on kergem otsustada võõrkeelse termini tõlkimatu ülevõtmise ja vastava olendidefinitsiooni lisamise kasuks. Eesti ja Lääne-Euroopa kultuuriruumi osas esineb osalist mentaalsuse kattumist, kuid piirkonniti ja valdkonniti tuleb ette ka tugevaid erinevusi, mida tõlkija peab teadma.

Ühe hea lahenduse leiab Tony Allani olendiraamatu eestindusest, kus ka sisuregistris on tõlkimatute olendinimetuste puhul toodud võimaluse korral sulgudes kompenseeriv lühidefinitsioon: far 
darring ("punane mees"), far gorta ("näljamees"), ceffyl dwr ("veehobune"), rakšasad ("näljased vaimud") (Allan 2009: 251-253).

\section{4. Üldnimetused ja isikunimed}

Üks keerulisemaid probleeme olendinimetuste ülevõtmisel just saksa keelest on küsimus, kas eelistada suur- või väiketähte, ehk teisisõnu, millal on tegemist üld- ja millal isikunimega. Saksa kirjapildis seda probleemi pole, kuna nimisõnad algavad niikuinii suure tähega. Eesti keele jaoks on ühtset reeglit raske leida.

Näiteks saksakeelse sõna Fangga vasteks jäi eesti keeles väikese tähega üldnimetus fangga, kuna saksa keeles kasutatakse sõna enamasti mitmuses (Fanggen, eesti vaste: fanggad) ja see märgib üldnimetusena teatud liiki hirmuäratavaid metsavaime.

Seevastu sõna Hehmann (eesti vaste: hehmann) kasutatakse enamasti ainsuses, ta on impersonaalne üksikolend, kes käib metsas ringi ja hüüab "heh" ja "hoi", kuid on mõeldud siiski üldnimetusena. Samuti kasutatakse sõna Rübezahl originaalis ainsuses, kuid tema puhul on tegemist konkreetse üksikolendiga, seetõttu sobib vasteks ka eesti keeles suurtähega kirjutatav isikunimi Rübezahl - seda hoolimata asjaolust, et nimetust oleks põhimõtteliselt võimalik sõnasõnaliselt tõlkida (Rübe - kaalikas, naeris; -zahl - arv, loendama) ja mitmetes süžeetüüpides on Rübezahli tegevuseks just naerite loendamine. Ent tõlkimine hägustaks seost originaalolendiga ja kaotaks seega ka osa olendi lokaalsest koloriidist.

Bercht esineb nii konkreetse personifikatsiooni nimena kui ka üldnimetusena (germaani kultuurist tuntud berchtijooksmine sarnaneb Eesti kombestiku martijooksmisega, sõna kasutatakse ka liiginimetusena: berchtid käisid öösel ringi), seega sõltub siin kasutus kontekstist.

Otsesed tõlkimatud laenud saksa keelest (eriti veel murdelisest saksa keelest), nagu enerbanske ja wicht on paratamatud uudissõnad, mis kirjutatud eesti keele reeglite kohaselt väiketähega tavasõna tasandil, kuna tegemist on üldnimetustega. Kindlate pärisnimede puhul säilib loogiliselt esisuurtäht (nt Ekke Nekkepen). 


\section{Sarnane kirjapilt, erinev sisu}

Huvitavaid avastusi pakkusid juhtumid, mille puhul mingi sõna saksa ja eesti keele kirjapilt on sarnane ja aimatav on isegi geneetiline seos, kuid käibel olevad sõnade tähendused on erinevad.

Eesti sõna $k r a t t$, mis märgib eesti keeles enda peremehele varanduse kokkukandjat, on keelelises mõttes tõlkelaen germaani sõnast Schratt, kuid tähendab eesti pärimuses sisult hoopis midagi muud, vastates pigem saksa usundis esinevale olendile nimega Drak. Saksa Schratt omakorda vastab eesti usundis olemuselt kõige enam mõistele painaja. Siia vahele mahub veel oletatav levikutee rootsi olendi skratt kaudu, kes sarnaneb funktsioonilt enam eesti usundi kratiga kui germaani Schratt.

Ka teine varavedajat märkiv nimetus (tuntud peamiselt Tartumaal ja kaugemal Lõuna-Eestis), nimelt puuk on pärit saksa keelest - see on tuletatud sõnast Puck, kuid originaaltermin Puck tähistab oma levikualal Põhja-Saksamaal hoopis teatud liiki majavaimu, mitte varakandjat. Seetõttu jäin deemonileksikonis sõna Puck eestindamisel segaduse vältimiseks originaalkirjapildi juurde.

Eriti värvikas näide mitmetähenduslikkusest on nimetus Ork, mis antiikmütoloogias märgib surmajumal Orcust, eeposes Beowulf kurja hiiglast, germaani rahvapärimuses merekoletist, luuletaja William Blake'i omamütoloogias esimeste inimeste mässumeelset last ja Tolkienil päkapikulaadseid mäekolle (vrd Colbert 2003: 101102). Vähe sellest, eesti usundis on ork (ja soome usundis horkka) hoopis mütoloogilise halltõve eufemism ning märgib mõningatel juhtudel ka katkuvaimu.

Mitmetel juhtudel on eesti kultuuris olemas nii nimevaste kui ka olendivaste, aga lokaalsetes joontes esinevad siiski erinevused. Neid on üsna raske mingi sõnavastega edasi anda, vajalik on pikem seletus või definitsioon.

\section{Paralleelnimetused ja alajaotused}

Peamurdmist valmistavad olukorrad, kui ühes keeles oli mingite teatud olendite jaoks olemas detailsem klassifikatsioon kui teises. 


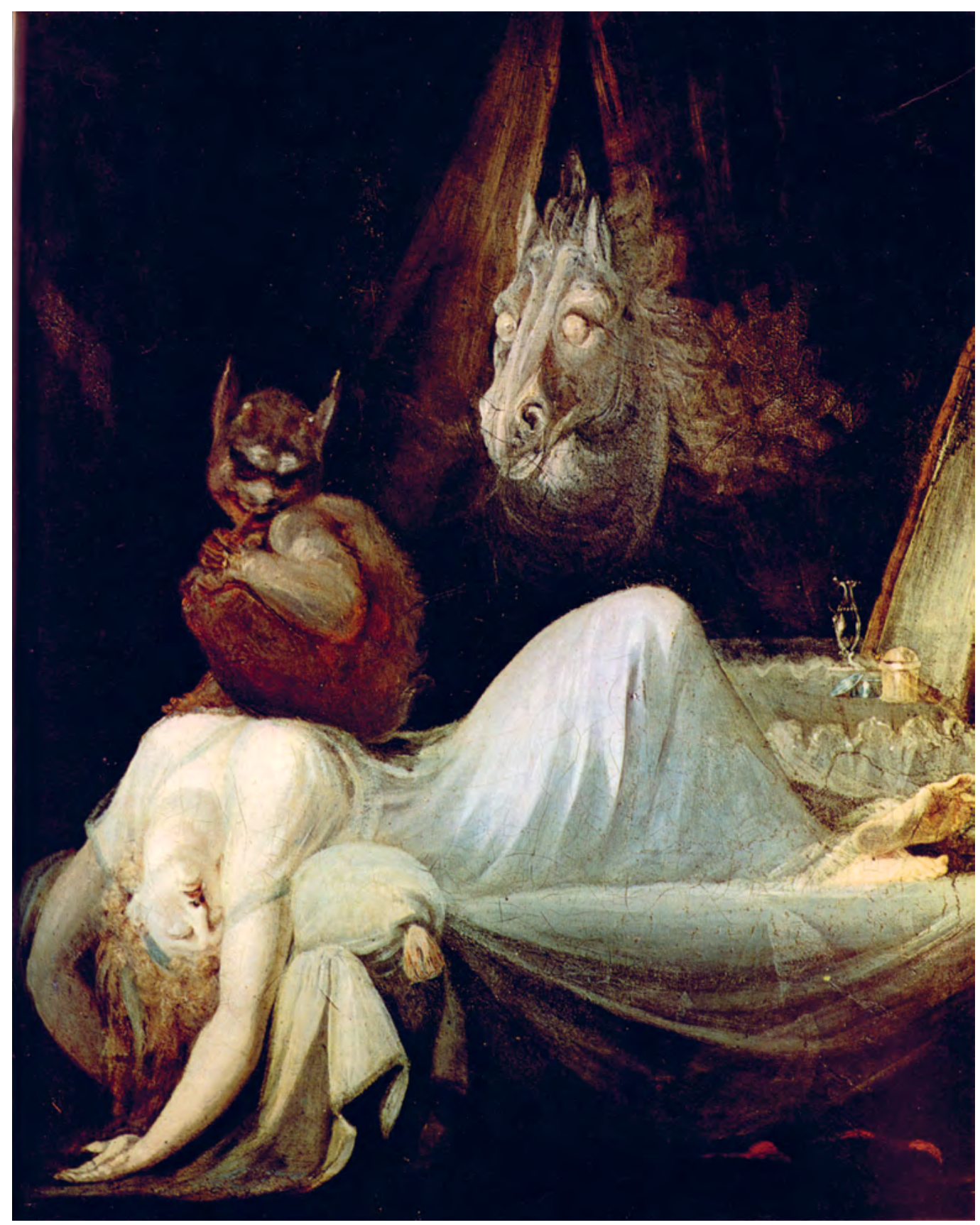

Luupainaja. Johann Heinrich Füssli. 1802. 
Näiteks eesti usundis on küll muistendid painajast populaarsed, kuid painajaolendi jaoks muid alternatiivseid nimetusi peale painaja ja luupainaja (ja nende derivaatide painakas, painjas jm) praktiliselt ei tuntagi. Seevastu on saksa keeles olemas Drud, Mahrt, Mahrrieder, Alp ja veel teisigi, mis käivad kõik üsna sarnaste painajaolendite kohta. Murdelises plaanis, tõsi küll, on märgata mõningaid eelistusi ühe või teise kasuks. Kuna eesti keeles piirkonniti ega murdeti painajaolendeid märgatavalt ei eristata, osutus mõttekaks säilitada lähedus saksa originaalterminitega, et erinevus siiski välja tuleks. Saksa Drud on üldjoontes nagu eesti usundi painaja, aga kuna saksa keeles on teda mõistest $A l p$ eristatud, pidasin selle vahe väljatoomise huvides vajalikuks jätta alles tsitaatsõna $d r u d$. Sama loogikat on järgitud peamiselt mõningates Ida-Saksa piirkondades kasutatava sõna Mahrt puhul, säilitades eesti vastes saksapärase sõnakuju mahrt, kuna siin on oluline ka geograafiline dimensioon - sama sõnatüvi kordub naabermaades (poola k mora, sorbi k murawa). Andes Mahrt'i vasteks lihtsalt painaja, läheks see lingvistiline seos kaduma. Alp on tõlgitud painajaks, kuna see on saksa keeles antud olenditegrupi kõige üldisem termin, painajaolendite katusmõiste.

Sarnased küsimused kerkisid üles seoses sõnaga Kobold - jätsin eesti vasteks koobold, kuigi see nimetus on eesti keeles vähekasutatav. Kooboldil on palju ühiseid jooni majavaimuga, kuid nende funktsioonid ja omadused pole siiski päris kattuvad. Samas viitab sõna Kobold keeleline taust pigem just sarnasustele kui erinevustele: Kob- keskülemsaksa keeles kobe, Kofen (säilinud nt uusülemsaksa sõnas Schweinekoben) tähendab (sea)sulgu, ruumi, maja. Teine silp -bold tähendab ülevaatajat, valitsejat. Kobold on seega 'majavalitseja'. Kibbermanni jt "Saksa-eesti sõnaraamat" pakub saksa sõnale Kobold vasteks 'ülemeelik majavaim, mäevaim', mis annab olendi olemust hästi edasi, kuid jääb siiski ümberütluseks. Tony Allani olendiraamatu eestinduses on kasutatud vastet kobold (Allan 2009: 12).

Eraldi kooboldilaadsete vaimumehikeste alaliigina esineb germaani usundis Wicht. Tundus mõttekas säilitada sama sõnakuju ka eesti keeles (wicht), et keeletundja jaoks jääks läbipaistvaks kesk- 
ülemsaksa keelest säilinud tähendusseos Wicht = 'olend, miski'. Sellega on ühenduses uusülemsaksa sõna nicht tekkimine vanaülemsaksa sõnast ni-wiht 'mitteasi, mitteolend, eimiski' (Petzoldt 2003: 211). Muutunud tähendusega on saksakeelne sõna Bösewicht, mida kasutatakse paha lapse kohta tähenduses 'paharet, marakratt'.

Huvitav näide on termin Elementargeister, mis germaani usundis märgib elementide (vesi-maa-tuli-õhk) personifikatsioone. Saksa kultuuris esineb seda mõistelist seost palju rohkemate olendite puhul kui eesti puhul, kus elementide järgi hierarhiate moodustamine on usundis üsna väheoluline. Eesti keeles on siiski olemas vaste elementaalid, kuid ilmselgelt pole see kunagi olnud rahvapärases kasutuses.

Järgnev on näide sellest, kuidas ühele saksa keeles üsna selgepiirilisele sõnale sobivad eesti keeles erinevad vasted, mis kõik edastavad mingeid lähtekeele sõna olulisi nüansse. Rahvakultuuri leksikon (Viires 1995) pakub sõna Zwerg eesti vasteks kääbus, kuigi kääbus on eesti usundis eraldi olendina üsna vähetuntud ja tal on pigem kurja ja pahatahtliku olendi maine. Sõna kääbus ise on vana ja seostub surnuteusuga (vrd kääbas), tähistades algselt hauas elajat (vrd Loorits 1949/57: 86). Juba Vestringi 18. sajandil koostatud sõnaraamatus esineb seos Härja Pölwe-Rahwas - Zwerge (Vestring 1998), mis oleks ilmselt üsna autentne vaste, kuid on sellise sõnakujuna praeguseks vananenud. Selle asemele on järkjärgult asunud sõna härjapõlvlane, mis on iseenesest Kreutzwaldi uudismoodustis. Härjapõlvlase olendikuju on germaani muinasjuttude toel (nt Lumivalgeke) ajapikku kujunenud järjest abivalmimaks ja heatahtlikumaks ning seega järjest kaugenenud kunagisest seosest surnuteusuga. Eesti pärimuses kannavad mõningaid saksa Zwergile omaseid jooni veel maa-alused, vähemal määral kasutatakse ka vastet päkapikk ja pöialpoiss. Otsustasin jääda vaste härjapõlvlane juurde, kuna see kannab endas kõige paremini mõiste keeleajaloolisi ja semantilisi tahke. 


\section{Sõna soo edasiandmine}

Saksa keeles annab sõnalõpu liide (nt -in) märku, et tegemist on naissoost olendiga, eesti keeles on samalaadne sõnamoodustus vähelevinud (nt kuninganna, Sööjatar), seetõttu tuleb eesti keeles sugu enamasti väljendada muul moel. Näiteks sõna Tödin vastena on võimalik kasutada sõna Surm ja lisada sulgudesse selgitus, et tegemist on just naissoost surmaga, kuna eesti usundis on olemas küll personifitseeritud surm (kes valdavalt ilmub mehe kujul), aga puudub eristus naissoost ja meessoost surmavaimude jaoks. Samuti oleks võimalik vaste naissurm, kuid ka selle puhul on paratamatult tegemist teatava kompromissiga; Tödin on rahvapärane nimetus, kuid naissurm on vaid sõna sisu edasiandev tehniline konstruktsioon. Samuti saab saksakeelsete olendinimetuste die Elbe või die Elbin eesti vasteks valida näiteks haldjas, haldjatar, naishaldjas või naissoost haldjas.

\section{Osa sõnast tõlgitav, osa tõlkimatu}

Seegi on kategooria, mille puhul sobivate vasteteni jõudmine ei tarvitse olla kerge. Niisuguste tõlkeolukordade lahenduseks võib olla see, et osa sõnast tõlgitakse ja osa transkribeeritakse, kuid asja teevad taas keeruliseks piirijuhtumid.

Kuidas tõlkida näiteks germaani olend nimetusega Heinzelmännchen: kas heinzel-mehike või transkribeerida kogu originaalsõna, jättes vasteks Heinzelmännchen? Lisandub veel see nüanss, et Heinz või Hinz esineb kohati sama olendi eesnimena: "Nagu muudegi majavaimude puhul tavaks (nt koobold), kannab ka tema inimesele omast eesnime Heinz või Hinz" (Petzoldt 2003: 83). Vähe sellest - ühe pärimuses teadaolevalt Lüneburgi lähedal elanud heinzelmännchen'i pärisnimeks olevat olnud Heintzelmann (samas). Teisalt kasutatakse sõna saksa keeles ka mitmusliku üldnimetusena die Heinzelmännchen, mõeldes selle all üldisemalt teatavaid koduhaldjalikke olendeid, keda näiteks perenaised endale meelsasti appi kutsuksid. Tundus otstarbekas jääda üldnimelise vaste heinzelmehike juurde. 
Sarnased küsimused kerkisid üles seoses sõnaga Kasermanndl - Eesti usundis pole ei vastavat olendit ega tabavat nimetusevastet. Pole raske järeldada, et sõna teine pool -manndl on kohaliku dialekti vaste sõnale Mann, kuid see ei ole eestindamisel abiks. Kasermärgib kohalikus dialektis karjasehütti, seega on äraseletatult tegemist karjasehüti-mehikesega, kes sügisel pärast karjuste lahkumist nende hüttides oma tempe teeb. Sõna-sõnalt tõlkides läheks aga kaduma nimetuse tore murdeline kõla, samuti olend ise, seetõttu pidasin vajalikuks jätta samasse teksti alles nii algse vormi kasermanndl kui kirjeldava vaste karjasehüti-mehike. Leian, et tõlkija peaks vähemalt püüdma selliste terminite tõlkimisel anda olulisi algkeele komponente edasi nii, et säiliks kombinatsiooni tähenduslikkus tervikterminina.

Saksa usundis esineb hulgaliselt mitmesuguseid naisolendeid, kelle nimetuse esimese poole moodustab sõna Frau: Frau Holle, Frau Hulda, Frau Hütt jt. Jätsin Frau Hütt vasteks ka eesti keeles Frau Hütt, mitte proua Hütt või emand Hütt, sest tegemist on kokkukuuluva sõnaühendiga, mis vahel esineb ka kokkukirjutatult Frauhütt. Samal ajal kohtab nimetust Holle saksa keeles nii ühendina Frau Holle kui ka ilma. Frau Holle vastena on varasemates tõlgetes esinenud ka emand Holle, seega tuleb siin tõlke valikul lähtuda haakuvusest konkreetse kontekstiga.

\section{Lõpetuseks}

Nagu nägime, sõltub olendinimetuste tõlkimisel sobiva sihtkeelevaste valik mitmetest asjaoludest - tõlke sihtrühmast, olendi- ja sõnavaste olemasolust sihtkultuuris, tähendusmuutustest jms. Tulevikuperspektiivina oleks nii tõlkijatele kui asjahuvilistele lugejatele abiks vastava veebipõhise, eri kultuuriareaale hõlmava sõnastikleksikoni loomine, mis sisaldaks lisaks definitsioonidele võimaluste piires ka illustreerivaid pärimustekste ja olendinimetuste võõrkeelseid vasteid ning oleks vastavalt vajadusele jooksvalt täiendatav. 


\section{Internetiallikad}

Eesti Ulmeühing: http://www.obs.ee/ taavi/esfa

Fantastikahuviliste portaal: http://www.dragon.ee

Olendite veebilehed: http://www.daemonen.de; http://www.geisterarchiv.de, http://www.enctype.de/Daemonen/frame.htm; http://www.eaudrey.com/myth Tolkieni-huviliste veebileht: http://www.keskmaa.ee

Tuulepesa foorum: http://tuulepesa.zzz.ee/

Ulmehuviliste veebileht: http://www.ulme.ee

\section{Kirjandus}

Agar, Michael 2006. Culture: Can you take it anywhere? - International Journal of Qualitative Methods, no 5: 2, pp. 1-16.

Allan, Tony 2009. Mü̈̈tilised olendid. Illustreeritud kogumik, mis tutvustab maailma kõige fantastilisemaid olendeid. Tallinn: Varrak.

Colbert, David 2003. Sõrmuste isanda võlumaailmad. Tallinn: Pegasus.

Eisen, Matthias Johann 1922. Näkiraamat. Tartu: Kool.

Florin, Sider 1993. Realia in translation. - Translation as Social Action. Russian and Bulgarian Perspective. Ed. Palma Zlateva. London: Routledge, pp. 122-128.

HDA I = Handwörterbuch des deutschen Aberglaubens. Band I. 1927. Hrsg. E. Hoffmann-Krayer, Hanns Bächthold-Stäubli. Berlin, Leipzig: de Gruyter.

Hiiemäe, Mall 2003. Maa-alused ja mailase rada. - Keel ja Kirjandus, 10, lk 760-769.

Kibbermann, Elisabeth, Kirotar, Salme, Koppel, Paula 1976. Saksa-eesti sõnaraamat. Tallinn: Valgus.

Loorits, Oskar 1949-1957. Grundzüge des estnischen Volksglaubens I-III. Skrifter utgivna av kungl. Gustav Adolfs Akademien för Folkslivsforskning 18:1. Lund. 
Manninen, Ilmari 1925. Etnograafiline sõnastik. Tartu: Loodus.

Marriott, Susannah 2009. Haldjad. Tallinn: Varrak.

Petzoldt, Leander 2003 [2010]. Väike deemonite ja vaimolendite leksikon. Tartu: Eesti Kirjandusmuuseumi folkloristika osakond [täiendatud uustrükk 2010].

Schleiermacher, Friedrich 1813.Ueber die verschiedenen Methoden des Uebersezens (24. Juni 1813). Internetis (vaadatud 31.01.2012):

http://www.muenchner-uebersetzerforum.de/Medien/Schleiermacher_Ausz. pdf.

Sturge, Kate [2012]. The Other on Display: Translation in the Ethnographic Museum. Aston University. Internetis (vaadatud 31.01.2012): http://www.soas. ac.uk/literatures/satranslations/sturge.pdf.

Torop, Peeter 2011. Tõlge ja kultuur. Heuremata. Humanitaarteaduslikke monograafiaid. Tallinn-Tartu: Tartu Ülikooli Kirjastus.

Torop, Peeter 2003. Tõlkesemiootika loeng Tartu Ülikoolis. Veebruar-aprill 2003. Konspekt.

Vestring, Salomo Heinrich 1998. Lexicon Esthonico Germanicum. Tartu: Eesti Kirjandusmuuseum. Internetis (vaadatud 31.01.2012): http://www.folklore. ee/ kriku/VESTRING.

Viires, Ants (koost.) 1995. Eesti rahvakultuuri leksikon. Tallinn: Eesti Entsüklopeediakirjastus.

Wiedemann, Johann Ferdinand 1876. Ausdem innerem und äusseren Leben der Ehsten. St. Petersburg: Buchdruckerei der Kaiserlichen Akademie der Wissenschaften. 


\section{Summary}

\section{Gnomes, imps and goblins. On the nuances of translating terms for supernatural beings}

Folk belief and mythological beings have not ceased to attract attention in the modern cultural communication. When we translate masterpieces of other cultures (e.g. folk epics), it is unavoidable to be informed about the original culture as well as its connections with the target culture. The same is true when we translate only one word (e.g. the name of a supernatural being or a cult object) - it is necessary to know its cultural background, even though the translation in the target language may also consist of only one word.

The paper gives an overview of some problems that occur in translating the names of supernatural beings. What to do if a word has no equivalent in the target culture or language, or when a word looks similar and is linguistically derived from the source language, but that has a different meaning in the target culture? The cases when one culture has a more elaborated system of certain supernatural beings than the other also create problems. In some instances, only a part of the name is translatable. Difficulties may arise when one and the same word can be used as a general term and as a personal name (especially characteristic to German language), or when there are differences in cultures based on monotheistic and polytheistic world views. Translating gendered names into languages where the gender is not marked by linguistic means also poses difficulties. Some possible ways of overcoming such translation problems are outlined in the article. It must be emphasised that solutions are not universal but context-based.

It is interesting to observe the role of certain translations in shaping the empirical experiences of individuals. In Estonia (as well as in many other civilised countries) numerous people perceive that they have contacts with the spiritual world. Yet the spectrum of supernatural beings met has widened in the course of cultural glo- 
balisation. As a result, new terms and ways of defining and describing the supernatural world have emerged.

Key words: translating, folk belief, supernatural beings, empirical experience, cultural context 